\title{
Aprendizagem infantil entre jogos e brincadeiras nos centros de educação infantil (CMEIS)
}

Child learning between games and children in children's education centers (CMEIS)

José Carlos dos Santos ${ }^{1}$

Adriane Dias Dias Souza ${ }^{2}$

\section{Resumo}

O artigo resulta de um estudo bibliográfico e de campo que teve como objetivodescrever uma realidade escolar e refletirsobre o tema aprendizagem infantil a partir dejogos e brincadeiras. A partir de algumas indagações já feitas por Vigotsky,elaborou-se as seguintes perguntas de pesquisa:o método lúdico de jogos e brincadeiras é adotado nos Centros de Educação Infantil?o Currículo para a Educação Infantil indica o uso desse método? Quais argumentos bibliográficos são indicados em defesa do método? Defendemos a importância de se utilizar o lúdico como recurso pedagógico no processo de ensino aportados em Vigostski e outros que afirmam que ao brincar a criança reproduz as atividades adultas de sua cultura e ensaia seus futuros papéis e valores. Metodologicamente, se define como pesquisa qualitativa e descritiva, com observação direta no CMEI, análisedeplanos de aula, entrevista com o professor.Como resultado desse processo de investigação, pode-se observar o surgimento da linguagem cognitiva e da sua importância para o planejamento das práticas pedagógicas; não somente para as atividades dirigidas, mas sobretudo, para as espontâneas para compreender os sentidos sub-reptícios que, em grupo, os alunos manifestam.

Palavras-chave: Cognição.Lúdico. Aprendizagem. Interatividade.

\begin{abstract}
The article results from a bibliographical and field study that had the objective to describe a school reality and to reflect on the subject of children's learning from games and games. Based on a few questions already asked by Vygotsky, the following research questions were elaborated: is the play and play method adopted at the Child Education Centers? Does the Curriculum for Early Childhood Education indicate the use of this method? Which bibliographic arguments are indicated in defense of the method? We defend the importance of using play as a pedagogical resource in the teaching process provided in

\footnotetext{
${ }^{1}$ Atualmente é professor Associado da Universidade Estadual do Oeste do Paraná. Departamento de Ciências Humanas. Docente da Graduação e Pós-Graduação Stricto Sensu. E-mail: professorjose-carlos@hotmail.com

2 Secretaria Municipal de Educação do Município de Cascavel, Paraná. E-mail: adrianedias1984@gmail.com
} 
Vigostski and others who claim that in playing the child reproduces the adult activities of their culture and rehearses their future roles and values. Methodologically, it is defined as qualitative and descriptive research, with direct observation in the CMEI, analysis of lesson plans, interview with the teacher. As a result of this research process, one can observe the emergence of cognitive language and its importance for the planning of pedagogical practices; not only for the directed activities, but above all for the spontaneous ones to understand the surreptitious meanings that the students manifest in a group.

Key-words: Cognition. Ludic. Learning. Interactivity.

\section{Introdução}

O presente artigo apresenta uma breve discussão sobre a aprendizagem por meio de atividades lúdicasde jogos e brincadeiras no processo de ensino na Educação Infantil. O estudo será apresentado em duas formas de exposição: um quadro teórico de referência sobre o tema e uma observação de campo.

A pesquisa de campo foi realizada por meio de observações diretas em um CMEI, no município de Cascavel, com o objetivo de descrever e analisar a forma como um professor de Educação Infantil atuante no pré-escolar I, com crianças de idade entre 3 e 4 anos, desenvolve alguns conteúdos propostos no Currículo para a Educação Infantil do Município de Cascavel. O intuito da observação foi o de perceber se o docente utiliza os recursos lúdicos, como jogos e brincadeiras,se reconhece sua importância nesse estágio de desenvolvimento e os modos como o professor planeja essas ações.

A pesquisa partiu de nosso interesse em defender a importância de se utilizar o lúdico como recurso pedagógico. Apontamos, com esta finalidade, os pressupostos teóricos de alguns autores como o de Vigotsky,que afirma que é brincando e jogando que a criança revela seu estado cognitivo, visual, auditivo, motor, seu modo de aprender e entrar em uma relação cognitiva com o mundo de eventos, pessoas, coisas e simbolos.

Rodrigues (2013), Pinto (1997), Ariés (1986), entre outros, reforçam essa perspectiva ao demonstrarem que a infância responde a uma perspectiva 
histórica e social na medida em que os adultos, segundo a sua cultura, modelam e remodelam o crescimento do novo ser visando sempre a sua adequação cultural. Nos estudos de Ariés (1986), podemos visualizar a construção de um quadro comparativo entre a infância da idade moderna e a infância dos dias atuais para demonstrar que se trata de uma construção sócio histórica, uma modelação social conforme os valores relativos a esses períodos.

Quanto ao levantamento de fontes, portanto, apontamos uma breve pesquisa bibliográfica como apoio de descrição de um estado da arte e para suporte à compreensão da pesquisa qualitativa, pois, segundo Minayo (1994, 2000), a pesquisa qualitativa responde a questões particulares e enfoca um nível de realidade que não pode ser quantificado. O estado da arte permite colocar o tema em relação com discussões já publicizadas, e assim dinamizar o próprio processo de produção do conhecimento. No procedimento qualitativo, também, as ações dos sujeitos envolvidos não podem ser descoladas de seus contextos, pois só adquirem sentido dentro desta esfera, espacial, temporalmente e socialmente (enquanto exercício em grupo). O levantamento de fontes foi realizado por meio de visita ao CMEI selecionado, entrevista direta com o professor, observação e análise de alguns planos de aula e observações em sala de aula.

\section{Discussão teórica}

O texto constitucional de 1988 incluiu creches e pré-escolas no sistema de ensino, formando com o Ensino Fundamental e o Ensino Médio a Escola Básica. Tal sistema, se por um lado dá sinais de uma boa articulação qualitativa, por outro, necessita de instrumentos que sistematizem o trabalho pedagógico realizado ao longo dessas etapas, sem impor o modelo de uma etapa à outra, em respeito à idade escolar, à cultura local e à formação docente. 
Neste impulso constitucional, também podemos alocar as novas Diretrizes Curriculares Nacionais da Educação Infantil (DCNEIs) aprovadas pelo Conselho Nacional de Educação em 2009 (Parecer CNE/CEB n² 20/09 e Resolução CNE/CEB $n^{\circ}$ 05/09). As Diretrizes podem representar a oportunidade para se pensar como e em que direção atuar junto às crianças, a partir de quais parâmetros e como articula-los ao processo de ensinoaprendizagem na Escola Básica.

Embora normativos, devemos reconhecer que estes princípios, por si só, não impactam no interior da escola. Docentes e equipe pedagógica são desafiados a construir propostas pedagógicas que, no cotidiano de creches e pré-escolas, dêem voz aos objetivos local, ao desejo da equipe e também, de alguma forma, se coadune às perspectivas das famílias e das próprias crianças, uma vez que estas irão atuar diretamente na significação dos conceitos formadores sobre o mundo e sobre si mesmas.

Este artigo busca apresentar os argumentos normativos amparados na leitura de ensaios bibliográficos que respondam ao desafio exposto e, ao mesmo tempo, como resultado de uma pesquisa qualitativa, aponta como se dá a experiência docente em resposta aos objetivos elencados.

\subsection{Jogos e Brincadeiras}

São muitos os autores que discutem sobre a importância do lúdico na Educação Infantil. Não há, no entanto, unanimidade quanto ao conceito ou idade ideal, nem sobre os efeitos acerca da aprendizagem que ele desperta na criança. Dentre as diferentes abordagens daqueles que aconselham sua adoção, percebe-se que os autores evidenciam os efeitos sobre o desenvolvimento físico e emocional da criança enas suas habilidades de interação grupal e familiar.

Com este sentido, Ramos, Ribeiro e Santos (2011, p. 42), se colocam na linha daqueles que defendem a adoção de jogos e brincadeiras, por acreditarem que são várias as contribuições no sentido de naturalizar, facilitar 
e envolver as crianças com a aprendizagem. Os autores ressaltam como efeito do lúdico sobre o desenvolvimento infantil,a formação do autoconceitopositivoque desembocam no desenvolvimento integral, já que por meio deatividades esta natureza, a criança se desenvolve afetivamente, convive socialmente e opera mentalmente. Ao mesmo tempo,ressaltam ainda que o jogo é produto da cultura, e seu uso permite a inserção da criança na sociedade. Neste sentido, jogar, culturalmente falando é uma atividade espontânea, realizada em grupo e que a finalidade de interagir, envolver, conviver. Se positivada como estratégia de ensino, poderia inserir a informação também de forma mais naturalizada e menos intrusiva no conhecimento infantil.

Se atribuirmos essas habilidades ao ato de brincar, podemos considerar que é uma necessidade básica, como é a nutrição, a saúde e a aprendizagem.Esta atribuição também deve ser afirmativa quanto ao desenvolvimento intelectual, uma vez que cria muitas possibilidades para que as crianças formem conceitos na medida em que relacionam ideias, estabelecem relações lógicas, desenvolvem a expressão oral e corporal, obtendo como resultado o desenvolvimento da linguagem cognitiva ${ }^{3}$.

A linguagem cognitiva enquanto resultado da ação/observação da criança sobre o espaço em que está interagindo, nada mais é do que a racionalização e interiorização de conceitos e valores construídos com o grupo. Segundo Lakoff e Johnson (1999), a natureza peculiar de nosso corpo modela a maneira como percebemos e interagimos com o mundo, e tem influência direta em como o categorizamos, conceitualizamose raciocinamos sobre ele. Como disseram Evans e Green, em outras palavras,

\footnotetext{
3 Por questão de delimitação da discussão, não adentraremos uma abordagem da temática da linguagem cognitiva, profundamente. Mas nos informa Ana Carolina Sperança-Criscuolo (2014) que a Linguística Cognitiva (LC) começou a se estabelecer como ciência a partir dos anos 1980; que "a noção de mente corporificada, segundo a qual mente e corpo não são entidades estanques, mas relacionam-se mutuamente, é central nesse paradigma (em oposição à tradição filosófica de mente como capacidade autônoma), e está fortemente relacionada ao processo de categorização: um processo básico de qualquer espécie animal, resultante de sua interação com o ambiente (o que permite, a partir do estabelecimento de padrões, o reconhecimento de alimentos, seres semelhantes, predadores etc. (p. 57).
} 
os conceitos a que temos acesso e a natureza da 'realidade' que pensamos ou da qual falamos são uma função de nossa corporificação: só podemos falar sobre o que podemos perceber e conceber, e as coisas que podemos perceber e conceber derivam da experiência corporificada (EVANS; GREEN, 2006, p.46).

A corporificação seria, portanto, uma espécie de ato fundador da linguagem cognitiva e que neste caso, apontamos como o ato de brincar. Neste sentido elencamos também o que pensam Lakoff e Johnson; para eles, o ato de brincar reforça habilidades sociais, reduz a agressividade, integra na sociedade e constrói independência de conhecimento.

Ampliando ainda mais esse entendimento da linguagem cognitiva mediante os jogos, Rodrigues vai mais adiante. Afirma que o jogo é essencial para a saúde física e mental, pois permite à criança as vivências do mundo adulto, o que possibilita a mediação entre o real e o imaginário (RODRIGUES, 2013). Neste sentido, destaca-se ainda a importância da brincadeira:

Estudar na infância somente o crescimento, o desenvolvimento das funções, sem considerar as brincadeiras, seria negligenciar esse impulso irresistivel pelo qual a criança modela a sua própria estátua. [...] Pela brincadeira ela desenvolve as possibilidades virtuais que afloram sucessivamente à superficie do seu ser, assimila-as e as desenvolve, une-as e as combina, coordena seu ser e lhe dá vigor. (CHATEAU, 1987, p. 14 apud RODRIGUES, 2013).

Depreende-se das afirmativas de Rodrigues e Chateauque brincar ou jogar 4 fazem parte "naturalmente" do crescimento infantil, da aprendizagem e da decodificação do mundo adulto.

Dirigido ou espontâneo, Vygotsky (1984) considera o ato de brincar relevante na constituição do pensamento infantil, pois é brincando ou jogando que a criança revela seu estado cognitivo, visual, auditivo, motor, seu modo

\footnotetext{
${ }^{4}$ Cabe ressaltar, no entanto, que mesmo que utilizemos os conceitos de brincar e jogar como sinônimos neste artigo, eles se distinguem. Podemos dizer que o jogo é a atividade com regras que definem uma disputa "que serve para brincar". Logo, ela é dirigida e controlada pelo professor visando um objetivo bem traçado. Brincadeira é o ato ou efeito de brincar, entreterse, distrair-se com um brinquedo ou jogo, mas que neste caso, não há intenção de controle e introspecção de determinado valor. Ambas podem produzir efeitos positivos para a aprendizagem infantil, pelos argumentos acima expostos.
} 
de aprender e entrar em uma relação cognitiva com o mundo de eventos, pessoas, coisas e símbolos, o que demonstra que

[...] durante o jogo uns objetos passam a significar muito facilmente outros, os substituem, se convertem em signos seus. Sabe-se igualmente que o importante não é a semelhança entre o brinquedo e o objeto que ele significa. O que tem maior importância é sua utilização funcional, a possibilidade de realizar com ajuda dele o gesto representativo. Cremos que só nisso está a chave para a explicação de toda a função simbólica dos jogos infantis. Uma bola de trapos enrolado numa madeira se converte em um bebê durante o jogo, porque permitem fazer os mesmos gestos que representam a nutrição e o cuidado com as crianças pequenas. No próprio movimento da criança, seu próprio gesto, é o que atribui a função de signo ao objeto correspondente, o que lhe confere sentido. (VIGOTSKI, 1982, p. 187188).

Nessa perspectiva, considera-se a brincadeira ou o jogo como expressivos na fase infantil e que abrem muitas possibilidades de ensino. Tal potencialidade implica com queo professor, como mediador entre o aluno e o conhecimento, atue, crie modelos de intervenção/provocação articulando o conteúdo curricular ao gosto e prazer da aprendizagem. No entanto, pela complexidade que representa, tanto na sua perspectiva de percepção quanto de execução, significa que o docente precisa ter algumas informações adicionais para reflexão. Ao mesmo tempo, é notório que exige do professor, no momento do planejamento do ensino, que demonstre domínio ou, pelo menos, que admita o recurso metodológico do jogar e brincar como um dispositivo pedagógico de ensino.

Assim, procuramos compreender, por meio do desenvolvimento desta pesquisa,de que forma que os professores daEducação Infantil desenvolvem os conteúdos propostos no Currículo para a Educação Infantil do Município de Cascavel de adoção, ou não, de jogos e brincadeiras.

Nossa busca teve início em uma busca no Referencial Curricular Nacional para a Educação Infantil. Encontra-se conceituado que brincar e jogar fazem parte de uma cenário de aprendizagem:

A fantasia e a imaginação são elementos fundamentais para que a criança aprenda mais sobre a relação entre as pessoas, sobre o eu e sobre o outro. Brincar funciona como um cenário no qual as crianças 
tornam-se capazes não só de imitar a vida como também, transformála. (BRASIL, 1998, p. 22).

A brincadeira ganha o status de linguagem principal da infância, inclusive motivada por algumas normativas oficiais. No entanto, o jogo para a aprendizagem ou como meio de aprendizagem, precisa ser dirigido e o professor é visto como um parceiro mais experiente, ou facilitador, que tem a função organizar o espaço e o tempo. É ele que deveofertar os brinquedos e provocar as brincadeiras, permitindo com que os alunos brinquem de forma espontânea e prazerosa entre si; sozinhos ou em interação com outros alunos, a atividade dirigida terá a função de atingir os objetivos do ensino formal. Se assim direcionado, pode-se afirmar, segundo Arce (2010), o fazdeconta toma o lugar de centralidade no trabalho pedagógico dentro das instituições de educação infantil.

A brincadeira é um tema que não está presente como conteúdo formal no currículo adotado pelo Município de Cascavel, como ademais apontam estudos sobre currículos municipais de outros lugares do Brasil.Contudo, defendemos que há dois momentos profícuos em que é possivel inseri-la, no caso em estudo. Primeiramente pelo fato de o Currículo ter como base os estudos de Vygotsky, Leontiev e Elkonin sobre a periodização do desenvolvimento, as particularidades e especificidades de cada idade. Segundo consta no documento, pode-se ler que

\footnotetext{
Leontiev (1978) parte do princípio de que cada período do desenvolvimento humano é marcado por uma atividade principal ou dominante, a qual desempenha função central na forma de relacionamento da criança com a realidade. Assim é desenvolvido o conceito de atividade principal, que Elkonin (1998) se utiliza para caracterizar a passagem de um periodo a outro. (CASCAVEL, 2008, p. 34).
}

A assim chamada atividade principal, segundo os autores, é a referência básica. Ela deve ser o foco do professor no sentido de compreender seu aluno e dosar o planejamento de ensino e a partir da compreensão de que a criança se confronta com seu espaço lugar. 
Em segundo lugar, conecto com o primeiro, é justamente a defesa que o currículo faz da necessidade enfocar o relacionamento da criança enquanto membro de um grupo social. A interatividade é apontada como a essência teórica e procedimental do currículo, logo, a nosso ver e pelos argumentos elencados neste texto, o jogo e a brincadeiras, são fundamentais facilitadores da aprendizagem.

Nos estágios de desenvolvimento humano, em conexão com a atividade principal que se inserem os jogos e brincadeiras como forma de experienciar o mundo, especialmente na fase entre 3 e 6 anos, quando as crianças exercitam os papéis sociais interagindo por meio de muitas linguagens, como a inversão de papéis e a imitação. Estas brincadeiras não são instintivas, e o que determina seu conteúdo é a percepção que a criança tem do mundo dos objetos humanos. Nas brincadeiras, as crianças representam ações que elas vivenciam, mas que ainda não tem condições reais para executá-las, como, por exemplo: dirigir um carro, conduzir uma motocicleta, etc.

Em outro momento da abertura curricular está no fato de, em não prescrevendo o conteúdo formal, aconselhar-se o lúdico. Ao descrever os pormenores da idade escolar entre 3 e 6 anos, afirma-se que:

A criança vai atuar com os objetos que são utilizados pelos adultos. Assim, acaba tomando consciência deles e das ações humanas realizadas com eles por meio da brincadeira. Esta pode ser compreendida pela criança como um propósito de agir como um adulto, ampliando assim seu mundo de possibilidades de ações. Desta forma, na brincadeira ela realiza ações complexas executadas pelos adultos em situações reais (CASCAVEL, 2008, p. 37).

Ainda com caráter explicativo da atividade principal nesse estágio do desenvolvimento, o documento menciona o lúdico, em que

A encenação - que é quando a criança atua por intermédio do brinquedo e a interpretação pessoal das tarefas sociais - contribui para o desenvolvimento do argumento, o qual depende da afinidade do tema lúdico com a experiência da criança. (CASCAVEL, 2008, p. 37, grifo nosso). 
Em conclusão, o Currículo não menciona diretamente, mas reconhece a importância do brinquedo como um meio de possibilitar a encenação que aqui, parece ter o sentido de interação social proposto por Vigotski.

\subsection{Infância}

Na organização ou compreensão de jogos e brincadeiras como meios de ensino, pressupõe-se que o educador tenha clareza sobre o desenvolvimento da infância. Contudo, a concepção de criança e deinfância foi mudando ao longo do tempo, sendo que, a visão que temos hoje em dia foi historicamente construída. A criança nem sempre foi vista como um ser em particular, mas sim como um adulto em miniatura, frágil e, algumas vezes, até um ser insignificante, em que “[...] a criança era tão insignificante, tão mau entrada na vida, que não se temia que após a morte, ela voltasse para importunar os vivos". (ÁRIES, 1986, p. 57).

Segundo Áries (1986), o termo e a duração da infância não era algo bem definido, podendo durar até os dezoito anos. Portanto, a criança, além de não ser considerada por suas particularidades, assumia responsabilidades não condizentes a sua fase de desenvolvimento, em que até mesmo suas roupas eram cópias fiéis das roupas utilizadas pelos adultos.

O sentimento ou preocupação com a infância tornou-se mais significativo a partir do século XVI e XVII, quando os costumes começaram a mudar,incluindo aqueles relacionados à educação. Dois novos sentimentos foram surgindo, o primeiro em quea criança, no ambiente familiar, passa a receber mais afetos e até ser paparicada. O segundo, ao contrário, era expresso por moralistas no século XVII, preocupados com a disciplina e a racionalidade dos costumes.

Somente a partir do século XVIII, a preocupação com aspectos referentes à criança, tais como higiene, saúde física, afeto e educação, tornaram-se assuntos sérios e aos poucos a educação foi tornando-se institucional. Segundo Pinto, 
[...] a infância constitui uma realidade que começa a ganhar contornos a partir dos séculos XVI e XVII. [...] As mudanças de sensibilidade que se começam a verificar a partir do Renascimento tendem a deferir a integração no mundo adulto cada vez mais tarde e, a marcar, com fronteiras bem definidas, o tempo da infância, progressivamente ligado ao conceito da aprendizagem e de escolarização. Importa, no entanto, sublinhar que se tratou de um movimento extremamente lento, inicialmente bastante circunscrito às classes mais abastadas (PINTO, 1997, apud MARAFON,1997, p. 44).

No entanto,ofertada apenas aos meninos e burgueses, sem separação por idades, a criança geralmente entrava com dez anos na escola e, consequentemente, no mundo dos adultos, na qual sua fase de desenvolvimento não era levada em consideração.

A infância ganhou espaço e importância, sendo reconhecida pela sociedade e pela família, a partir do século XIX e XX quandoa criança passa a ser vista como um ser em desenvolvimento, com particularidades, necessitando de cuidados específicos. Felizmente, tanto a concepção de infância quanto a de criança tem mudado;ela vem ocupando uma posição diferente na sociedade na qual é agora considerada como um ser humano portador de desejos e movido por esses desejos, um ser singular, exemplar único da espécie humana, que tem uma história e que interpreta o mundo. É, assim, um sujeito que age no mundo, que produz a si mesmo e que é produzido atravésda educação. (CHARLOT, 2000, p. 33).

Este movimento social de mudança da infância impulsiona, inclusive, a mudança nos modos de brincar e os modos como pedagogicamente deve ser tratado.

\section{A periodização do desenvolvimento e a importância da brincadeira e atividades lúdicas no pré-escolar}


Elkonin (1987) procurou periodizar o desenvolvimento infantil em estágios, baseando-se no conceito de atividade principal ou dominante de Leontiev (1978), que afirma que a atividade dominante não é aquela que a criança mais realiza, mas a que tem maior impacto em seu desenvolvimento psíquico, como atesta:

\begin{abstract}
A atividade dominante é [...] aquela cujo desenvolvimento condiciona as principais mudanças nos processos psíquicos da criança e as particularidades psicológicas da sua personalidade num dado estágio do seu desenvolvimento. (LEONTIEV, 1978, p. 293).
\end{abstract}

Os estágios de desenvolvimento perscrutariam maneiras diferencias de como a criança interagem com o seu meio social. Conforme Facci (2004), os estágios do desenvolvimento são: comunicação emocional do bebê,que ocorre desde as primeiras semanas de vida até mais ou menos um ano, constituindose como a base para a formação de ações sensório-motoras de manipulação. Neste período, o bebê utiliza vários recursos para se comunicar com os adultos, como o choro, sorriso, balbucio, movimento de braços e pernas, reação a sons e luzes, etc. Nesse primeiro ano de vida, o bebê é totalmente dependente do adulto, sendo este o principal mediador de seu contato com a realidade. Em um segundo momento, entre o primeiro e o terceiro ano de vida, a atividade principal passa a ser a objetal-instrumental ou objetalmanipulatória, que dá lugar à assimilação do uso social dos objetos e, para que ocorra esta assimilação, é necessário que os adultos medeiem as ações das crianças, pois os objetos que manipulam carregam conteúdos sociais, culturais, morais e éticos, já que foram produzidos ao longo da história humana. Primeiramente, a criança irá manipular este objeto para, em seguida, por meio da mediação, compreender sua função social.

Na sequência, no período pré-escolar, a atividade principal passa a ser o jogo ou a brincadeira.As brincadeiras não são instintivas e o que determina seu conteúdo é a percepção que a criança tem do mundo dos objetos humanos. Assim, elavai representar ações que vivenciam, mas que ainda não tem condições reais para executá-las como, por exemplo, dirigir um carro, 
trabalhar, conduzir uma motocicleta, usar sapatos dos adultos, etc. Mas é justamente devido à sua "incapacidade" que um bom método pedagógico pode direcionar para os conteúdos formais para que haja a formação de conceitos mais amplos.

Neste período pré-escolar,um objeto pode ter outras funções, por exemplo: um cabo de vassoura pode ser transformado em um cavalo, um pedaço de madeira em um pente para pentear sua boneca. Isto demonstra que

[...] durante o jogo uns objetos passam a significar muito facilmente outros, os substituem, se convertem em signos seus. Sabe-se igualmente que o importante não é a semelhança entre o brinquedo e o objeto que ele significa. O que tem maior importância é sua utilização funcional, a possibilidade de realizar com ajuda dele o gesto representativo. Cremos que só nisso está a chave para a explicação de toda a função simbólica dos jogos infantis. Uma bola de trapos enrolado numa madeira se converte em um bebê durante o jogo, porque permitem fazer os mesmos gestos que representam a nutrição e o cuidado com as crianças pequenas. No próprio movimento da criança, seu próprio gesto, é o que atribui a função de signo ao objeto correspondente, o que lhe confere sentido. (VIGOTSKI, 1982, p. 187188).

Sobre esse mesmo aspecto, Elkonin (2009) reforça a importância do jogo e das atividades lúdicas que contribuem significativamente para o desenvolvimento infantilao levantar hipóteses quanto ao uso da significação lúdica:

[...] inserem-se no jogo objetos substitutivos de objetos reais que recebem um nome adequado à sua significação lúdica; complica-se a organização das ações, a qual adquire o caráter de concatenação reflexiva da lógica das conexões vitais; produz-se uma síntese das ações e sua separação dos objetos; aparece a comparação de suas ações com as ações dos adultos e de acordo com isso, a criança atribui-se o nome de um adulto; opera-se a emancipação a respeito do adulto, apresentando-se este à criança como modelo de ação e, simultaneamente, surge a tendência para atuar com independência, mas como adulto. (ELKONIN, 2009, p. 230-231).

Ottoni e Sforni(2012) reforçam esta ideia, pois consideram que:

Leontiev, seguindo os mesmos princípios de Vigotski, afirma que a atividade lúdica é a principal para o desenvolvimento do psiquismo no período pré-escolar, porque para imitar algo ou alguém, além de a 
criança incorporar formas de comportamentos sociais, precisa colocar em movimento funções psíquicas como atenção, percepção, memória e imaginação e, nesse processo, as desenvolve. Nessa atividade também podem surgir necessidades e interesses que correspondem ao que é efetivamente esperado em um momento posterior como o interesse pela leitura, pela escrita, pelos animais, plantas, universo, enfim, interesse por conteúdos que são abordados sistematicamente na escola a partir das séries iniciais do ensino fundamental.(OTTONI; SFORNI, 2012, p. 9).

Neste sentido, destaca-se a importância em se trabalhar o jogo no período pré-escolar. Além de proporcionar aos alunos atividades lúdicas, considerando a atividade principal de cada período de desenvolvimento, é possivel e desejável que o educador articule os conteúdos propostos pelo Currículo e alocados nas diversas disciplinas - História, Geografia, Língua Portuguesa - com movimentos, cores, "passeios" a outros ambientes, encenações espontâneas e dirigidas para que o lúdico intermedeiea experiência e o exercício do conhecimento.

\section{Metodologia ou Método de análise}

Como referido na introdução, além da pesquisa bibliográfica, o artigo descreve o resultado de observações de campo. O foco da pesquisa foi um professor atuante no pré-escolar em um Centro Municipal de Educação Infantil do município de Cascavel. Partimos do pressuposto que a fundamentação em autores da corrente construtivista possibilita considerar os jogos e brincadeiras como elemento formador do conhecimento, imaginação e afetividade da criança.

O CMEI possui 6 turmas: Berçário, Maternal I, Maternal II, Pré-I Integral e duas turmas de Pré-I Período Parcial. Ao todo são 9 professores que atuam em sala. O CMEI atende 96 crianças, 75 em período integral e $21 \mathrm{em}$ apenas um período, manhã ou tarde, distribuídos em 5 salas. Oprofessor observado foi apenas um, atuante nopré-escolar, o qual foi escolhido por trabalhar diretamente com os alunos com idade entre 3 e 4 anos. 
A escolha obedeceu à estratégia de aproximação do estágio de desenvolvimento ou idade escolar dos alunos. Não houve preferência ou preterimento em relação ao professor, disciplina ou método de ensino. A periodização do desenvolvimento - segundo a referência acima descrita - está na fase das brincadeiras e jogos, bem como pela experiência de atuação e também pelos conteúdos contemplados no Currículo para a rede pública municipal de ensino de Cascavel. Foi realizada uma entrevista com o professor, observação de algumas aulas e a análise dos planos de aula com a finalidade de perceber conexões, reflexões, referências e bibliografias que mencionassem jogos e brincadeiras no processo de ensino.

Depreende-se que, pela natureza da pesquisa, ela não se define como uma pesquisa quantitativa, de estudo de caso ou que permita a construção de estatísticas. Ela revela-se como uma pesquisa qualitativa, ao lado dos dados objetivos de campo - me refiro ao planejamento educacional dos docentes do CMEI - que parece ser um caminho viável para o empreendimento. Minayo (1994, 2000) aponta que a pesquisa qualitativa responde a questões particulares e enfoca um nivel de realidade que não pode ser quantificado. Ao mesmo tempo, a autora ressalta que a pesquisa qualitativa não produz resultados individualizantes e desconectados da realidade social, poisenvolve um universo de múltiplos significados, motivos, aspirações, crenças, valores e atitudes em relação aos grupos nos quais está imerso o sujeito. A autora defende que qualquer investigação social deveria contemplar uma característica básica de seu objeto, que é o aspecto qualitativo. Ao mesmo tempo, a pesquisa qualitativa por ter sido realizada a campo, com coleta direta e com observação, também se definiu como etnográfica porque registramos comportamento, expressões, gestos e falas de alunos e professores em diversos momentos da vivencia escolar.

Por outro lado, segundo a pesquisadora Marli Eliza de André (2000), autora de A pesquisa no cotidiano escolar, em uma abordagem qualitativa, a teoria vai sendo construída e reconstruída no próprio processo de pesquisa, ocorrendoo mesmo com as opções metodológicas que vão sendo gradualmente 
explicadas e redefinidas. A análise ocorre paralelamente à observação, na medida em que o pesquisador seleciona aspectos que devem ser explorados e decide quais os que devem ser abandonados.

Também adotou-se a perspectiva bibliográfica que serviu para situar o estado da arte sobre o tema aqui descrito. Pretendeu-se, com tais fontes e discussões teóricas, compreender melhor o problema da pesquisa que se configura como sendo a defesa da importância de brincadeiras e jogos no processo de ensino e aprendizagem.

\section{Análise dos dados}

\subsection{Descrição dos dados}

O relatório a seguir foi construído a partir daanálise dos planos de aula, das observações em sala e da entrevista com uma professora atuante na Educação Infantil na rede municipal de ensino da Cidade de Cascavel. A professora é formada em pedagogia há um ano e meio por uma instituição privadae atua na Educação Infantil há um ano. Trata-se deseu primeiro ano de trabalho no CMEI, local no qual foi realizada a pesquisaeonde assumiu uma turma de pré-escolar, com crianças em idade entre 3 e 4 anos, na metade do ano letivo.

\subsubsection{A experiência da educadora}

A professora está no início de sua atuação na Educação Infantil. Em alguns momentos durante a entrevista, demonstrou certa insegurança com o planejamento e execução de suas atividades. Afirmou que considera o Currículo da rede pública municipal de ensino de Cascavel, (principal 
instrumento utilizado pelos professores, pois nele estão organizados todos os conteúdos que deverão ser trabalhados ao longo do ano letivo) "muito vago", pois "ele aponta o conteúdo, mas não dá subsídio".

Quando insistimos em saber o que seria "subsídio", ela deixa claro que se refere ao conteúdo propriamente dito, alternando entre metodologia e conteúdo. Esclareceu que, embora haja uma relação de conteúdo, eles não têm profundidade. Em relação ao lúdico, que embora o mencione, não há um indicativo ou uma reflexão mais profunda que seja capaz de dirimir dúvidas, pois "todas as dúvidas em relação aos conteúdos não conseguiencontrar respostas no Currículo, encontrando apenas poucas dicas para sanar suas dúvidas".

Essa lacuna de informação indicada pela educadora é sanada pela busca de informação. Ela diz que quando precisa pesquisar,utiliza a internet, pois considera um meio mais rápido e eficaz para relembrar certos conteúdos e conceitos. Ressalta, no entanto, que quando vai ensinar os conteúdos propostos no Currículo para a Educação Infantil, não precisa se aprofundar tanto, devendo ser realizado de forma mais lúdica. Indagada sobre qual o sentido de "não precisar aprofundar", a professora explicou que, dada a idade das crianças, a aprendizagem não ocorre de forma conceitual, mas pela demonstração e em formas variadas que não somente a escrita.

A professora assegura que o Currículo aponta o lúdico como componente curricular, expondo formas e exemplos de como trabalhá-los, mesmo que, como afirmou anteriormente, de forma muito vaga. "O lúdico tem que ser uma metodologia de ensino, principalmente nesta faixa etária"; sabendo desta importância, diz que em seu plano de aula inclui atividades lúdicas, como: pecinhas, massinha de modelar, quebra-cabeças, brincadeiras no pátio, caixa de areia e parque, bem como o resgate de brincadeiras antigas, Coelhinho Sai da Toca, além de trabalhar regras e profissões de forma lúdica, por meio de brincadeiras de papéis sociais.

Segundoa professora, a sua formação acadêmica tratou do tema de forma insuficiente;mas ela enfatizou a importância de atividades lúdicas no 
processo de ensino e aprendizagem e afirma que compreendeu tal importância principalmente durante os estágios realizados, momento no qual aprendia de forma prática preparar atividades, como, por exemplo: trabalhar sobre o ar confeccionando juntamente com os alunos cata-ventos, vagões para montar um trem explorando o conteúdo cores, brincar de bingo explorando os numerais.

Em relação à brincadeira, a professora também considera importante contemplar um momento da rotina para explorá-las, e esclarece que garante estes momentos principalmente na recepção pela manhã, quando dispõe os brinquedos; destaca também as atividades externas (no parquinho) quando as crianças ficam mais livres para brincar e em algumas aulas quando consegue atrelar o conteúdo trabalhado à brincadeira, pois, segundo ela, não é em todo conteúdo que é possível contemplar a brincadeira, o lúdico.

Quando perguntada sobre a aprendizagem dos alunos, se ela consegue perceber se aprendem melhor e de forma mais significativa o conteúdo trabalhado, a professora afirma que sim, que consegue perceber um maior interesse principalmente pelos alunos que apresentam maior dificuldade de concentração e atenção, sendo que, além de se interessarem mais, conseguem aprender de forma mais significativa.

\subsubsection{Descrição das observações}

A turma de pré-escolar,na qual foramfeitas as observações, é uma turma parcial com 11 alunos frequentada no periodo da manhã, das 07h30minàs 11h30min, e 10 alunos no período da tarde, das 13h30minàs 17h30min, ambas atendidas pela mesma professora. Foram realizadas 16 horas de observações durante quatro dias no período da tarde. Pôde-se observar que a professora segue rigorosamente seu plano de aula, que é bem estruturado com todos os elementos necessários. Nesses planos, foram contempladas as disciplinas de Matemática, Lingua Portuguesa, Arte, Educação Física, História e Ciências de forma articulada. 
No primeiro dia de observação, a professora trabalhou as disciplinas de Ciências e Português explorando os conteúdos: Prevenção de acidentes, Relação grafema/fonema (sonorização) e Leitura: função social da escrita. A professora preparou a recepção dos alunos com o alfabeto móvel em E.V.A,disposto sobre as carteiras para os alunos manipularem. Cada um recebeu letras diversas, manipularam e alguns tentaram falar o nome de letras, sendo que três alunos conseguiram associar a primeira letra de seu nome.

Em seguida, todos os alunos foram até o refeitório para o lanche da tarde.Assim que voltaram para a sala, a professora chamou os alunos para irem até a frente, individualmente, contar as letras do alfabeto que estava colado na parede, auxiliando os que tinham dificuldade.

Na sequência, cantou uma música dos dias da semana e realizou escrita no quadro com o nome da cidade, dia, mês e ano, nome do CMEI e nome dos alunos, registrando a letra inicial e contando quantos estavam presentes. Logo após, iniciou uma discussão perguntando: O que é acidente doméstico? Alguns alunos tentaram responder dizendo que caíram e rasparam a perna, outro que se machucou no poste.A professora conversou sobre os perigos de mexer no fogão e se queimar, que não pode mexer nos produtos de limpeza e muito menos ingeri-los e cuidar para não pisar no chão molhado.

Posteriormente, mostrou dois vídeos sobre os perigos domésticos. A professora escreveu um cartaz com a música de um dos vídeos, chamada Perigo!, e realizou uma atividade de leitura, explorando a interpretação e o som da letra inicial das palavras para comparar as que começavam com a mesma letra e som, por exemplo, machucar/mais.

Após esse momento,a professora entregou um texto impresso para que os alunos encontrassem e marcassem as vogais. Os alunos demonstraram interesse, mas todos necessitaram de auxílio para conseguir realizar a atividade proposta. Em seguida, a professora organizou os alunos em fila e com ajuda da sua auxiliar, realizou um passeio nas ruas próximas ao CMEI para mostrar aos alunos os cuidados ao atravessar a rua, que é preciso olhar 
para os dois lados, observar as placas de trânsito, cuidar para não cair, não tropeçar, entre outros. Os alunos ficaram bastante empolgados no passeio, chamando atenção também para outros elementos, como cachorro, árvores, pessoas que estavam passando, etc. Após o passeio, todos foram ao refeitório jantar e quando voltaram para a sala,depois da higiene, a professora distribuiu diversos livros de histórias infantis para os alunos visualizarem as imagens, e aos poucos foram indo para casa.

No segundo dia de observação, a professora explorou as disciplinas de Matemática e Língua portuguesa, trabalhando os conteúdos: Exploração de figuras tridimensionais (sólidos geométricos), Classificação de figuras planas e não planas e Adequação e ampliação de usos e contextos. Na recepção, distribuiu peças do Pequeno Engenheiro, que têm formatos diversos e formas geométricas (blocos lógicos), para os alunos manipularem, estimulando-os e auxiliando-os para formarem castelos, casas, entre outros.

Logo após o lanche, a professora iniciou a aula escrevendo o cabeçalho no quadro com o nome da cidade, data, dia da semana, nome do CMEI e professoras. Na sequência, organizou todos os alunos sentados no chão e entregou um giz escolar, solicitando que desenhassem bolas (círculos) no chão. Depois, questionou-os: com qual forma geométrica se pareciam as bolas? Os alunos responderam círculo. A professora questionou quais os objetos da sala tinham formato de círculo: o relógio, o fundo da lata, a tampa do pote de massinha. Após, distribuiu um pedaço de massinha para todos fazerem bolas, passando por cada aluno pedindo que contasse quantas bolas haviam feito, auxiliando os que tinham dificuldades. Também questionou qual era o formato da bola feita com massinha e explicou que a bola de massinha é diferente (esfera, forma não plana e tridimensional) da bola que foi desenhada no chão com giz (círculo, forma plana e bidimensional) e, ainda, que a do chão não rola e a de massinha rola (rolou para demonstrar).

Em seguida, organizou os alunos em círculo e mostrou as formas geométricas planas, com os blocos lógicos, e as não planas, feitas com papel, sendo: cubo, cone, pirâmide, cilindro e esfera (bolinha de isopor). A professora 
disse que são tridimensionais e pediu para que os alunos manipulassem os blocos lógicos e os feitos em papel. Durante a atividade, a professora ficou o tempo todo mediando e explicando individualmente o nome de cada peça e suas características.

Posteriormente, guardou as formas e organizou os alunos sentados nas mesinhas em fila, distribuiu os cadernos de desenho, pegou as peças do jogo Pequeno Engenheiro e disse que montaria um prédio e, ao lado, uma casinha sobre uma mesinha à frente. Solicitou, ainda, que os alunos desenhassem os dois no caderno, auxiliando sempreaqueles com dificuldade. Nesse momento, os alunos se dispersavam bastante, levantando do lugar, cutucando o colega e conversando. A professora e sua auxiliar precisaram auxiliar todos os alunos para realizarem a atividade, sendo que um deles não conseguiu nem mesmo com ajuda. Ainda nesse dia, a professora levou os alunos ao gramado em frente ao CMEI e entregou vários blocos lógicos e bolas, pedindo para que manipulassem e observassem os que rolavam e os que não rolavam. A proposta durou pouco tempo, pois os alunos logo começaram a brincar com as bolas livremente, chutando, rolando, lançando, correndo, etc. Após o jantar, a professora levou os alunos novamente ao gramado para brincarem com as bolas até a chegada dos pais ou responsável.

Nesse dia, os alunos demonstraram-se muito dispersos e não queriam mais atividade dirigida. Passaram a chutar a bola livremente e não obedeciam ao chamado da professora e da auxiliar de sala.

No terceiro dia, a professora explorou as disciplinas de Português, Matemática, Arte e Educação Física, trabalhando com osconteúdos: Ideia de representação, Registro de numerais de 0 a 9, Artes visuais: Forma e coordenação motora ampla. Na recepção, organizou os alunos sentados nas mesinhas em fileiras e distribuiu um livro de literatura infantil para cada um, pedindo que observassem as figuras presentes em cada livro. Aos poucos, os alunos foram perdendo o interesse, levantando da cadeira, andando pela sala, conversando com os colegas, em que alguns queriam trocar de livro, demonstrando, novamente, falta de interesse com o escrito, o que levou a 
professora a guardar os livros quando percebeu que já não havia mais interesse, e pediu para todos se sentassem em suas cadeiras, visto que já estava quase na hora do lanche.

Após todos voltarem do lanche, a professora iniciou uma atividade dirigida, começando pelo cabeçalho, com nome da cidade, data, dia da semana, nome do CMEI e professoras, sempre perguntando aos alunos. Em seguida, contou a narrativa A história das formas geométricas, em que os alunos demonstraram bastante interesse, prestando atenção na história.

$\mathrm{Na}$ sequência, mostrou as formas geométricas recortadas em papel camurça e papel cartão, questionando os alunos sobre quantos triângulos, círculos, quadrados e retângulos tinham no desenho que se formava (uma casa, um menino e uma árvore). Os alunos fizeram tentativas para contar as formas, demonstrando interesse na atividade proposta. Após, a professora distribuiu uma atividade impressa com o desenho das formas geométricas presentes na história e as formas recortadas em papel dobradura e camurça, sendo triângulo (vermelho), quadrado (azul), círculos (amarelo), retângulo (marrom), para montarem o desenho encontrado na história. A professora sentou-se individualmente com os alunos para auxiliar na montagem e colagem das figurase, em seguida, pediu para cada um contar quantos triângulos, quadrados, círculos e retângulo tinham auxiliado na contagem, e que deveriam registrar ao lado do desenho. Somente um aluno não conseguiu concluir a atividade, mesmo com ajuda.

No quarto e último dia observado, a professora propôs a atividade de forma mais lúdicapor meio de uma brincadeira chamada Jogo das cadeiras de Natal, explorando as disciplinas de História, Língua portuguesa e Educação Física comoconteúdo: diversões: diferentes formas de diversão e lazer, características das brincadeiras e dos brinquedos do passado e do presente, Leitura: aspectos verbais e não verbais e coordenação motora ampla. Para a recepção, a professora apenas organizou os alunos sentados em fileiras e distribuiu os livros de literatura infantil para que manipulassem e 
observassem as figuras, realizando leitura imagética. Enquanto isso, ela terminava de organizar o material que usaria na atividade proposta.

Logo após o lanche, quando voltaram para a sala, a professora organizou as cadeiras em círculo e em cada uma delas colou um símbolo natalino com o respectivo nome, por exemplo: a figura do sino e a palavra sino abaixo da figura. A professora explicou aos alunos que esta é uma brincadeira antiga realizada por crianças que não tinham brinquedos e que, ao invés de utilizarem um aparelho de som, eles mesmos cantavam a música. Assim, a professora colocou uma música natalina e todos tiveram que girar em volta das cadeiras, de modo que, quando a música parasse, cada criança deveria sentar-se em uma cadeira. Após as crianças estarem sentadas, a professora pegou um saquinho e sorteou uma palavra, a primeira foi bengala, etodas olharam curiosas para a própria cadeira. A aluna que estava sentada na cadeira com a palavra sorteada precisou sair da brincadeira, e assim respectivamente atéque todas as palavras fossem sorteadas, restando apenas um último aluno sentado, que foi o vencedor.

A professora explicou que ninguém precisava ficar triste ao sair da brincadeira, pois haveria várias rodadas e cada um teria a oportunidade de ser o vencedor. Dessa forma, os alunos demonstraram bastante interesse e empolgação na atividade, sendo que o mais interessante foi poder observar como conseguiam relacionar a palavra sorteada ao símbolo. Quando o colega demorava para perceber, todos apontavam para a cadeira que estava o símbolo sorteado. A professora repetiu diversas vezes a brincadeira proposta, levando os alunos até o pátio para ensaiarem uma música natalina que iriam apresentar na cantata de Natal. Após o jantar, a professora levou todos os alunos ao parque onde todos brincaram livremente até a chegada dos pais ou responsável.

\subsection{Análise das fontes}

\subsubsection{Desempenho da professora}


Em relação à educadora, é preciso considerar primeiramente a sua recente formação. Não há um acúmulo de experiência com o qual possa contar para o planejamento e execução do processo de ensinar. É preciso refletirmos sobre o fato de, apesar de a escola ser um coletivo, o trabalho pedagógico ser realizado de forma individual. Contudo, demonstrou segurança no desempenho das ações, interesse e posicionamento crítico em relação ao Currículo quando, percebendo a necessidade de mais informação, o considerou limitado.

Quanto a sua recente formação, ainda observamosa falta do fazer prático. Embora apresente destreza para buscar informação, tanto de referencial quando de formas, ainda lhe falta acúmulo de saber fazer; é este tipo de experiência que resulta em estratégias de controle de turma e de acompanhamento individual. O fazer pedagógico da iniciante está sendo feito de forma isolada, sem acompanhamento e partilha com profissionais mais experientes.

Ao apontar a internet como fonte de pesquisa, levanta um alerta, visto que há muitas informações desencontradas ou superficiais obtidas por esse meio. Contudo, ao ressaltar que a busca pela rapidez e porque tem o cuidado de dosar a informação e variabilidade na forma de ilustrar o conhecimento, demonstra que essa atitude de busca na internet não compromete a qualidade, ao contrário, parece lhe fornecer elementos satisfatórios para ela própria surfar no intermeio de outras linguagens, compreendê-las e usar como ferramenta de ensino.

A turma da professora é também bastante heterogênea e agitada, o que the provoca a necessidade de variar as atividades e oferecê-las constantemente como forma de não permitir a dispersão. Esses dois ingredientes - turma agitada e professor recém-formado - são inicialmente fatores que adquirem estabilidade com o tempo.

\subsubsection{Desempenho dos alunos}


Quanto às observações dos alunos, pode-se descrever que a turma era bastante agitada e heterogênea.Segundo a professora, nenhum deles havia frequentado a Educação Infantil, portanto, tinham bastante dificuldade em aceitar regras e a maioria não havia se adaptado à rotina escolar, mesmo já estando no final do ano letivo. Muitos dos integrantes, inclusive, tinham dificuldade quanto à autonomia,como ir ao banheiro, realizar higiene pessoal e trocar de roupa sozinhos. A oralidade da maioria era de difícil compreensão; alguns apresentavam fala infantilizada, como um aluno, que era o que demonstrava mais dificuldade nas atividades propostas, que falava apenas as palavras papai e mamãe, encontrando-se, ainda, em processo de desenvolvimento da fala aomostrar bastante dificuldade para se comunicar. A maioria apresentava dificuldadescom relação à atenção e concentração. No entanto, a professora afirma que quando conseguia trabalhar de forma mais lúdica o conteúdo proposto, os alunosexprimiam maior interesse, sendo mais participativos nas atividades. Isso foi constatado durante a observação, principalmente no dia em que a professora propôs muito conteúdo.

\section{Considerações finais}

Segundo os autores referenciados ao longo deste trabalho, jogos e brincadeiras são estratégias de ensino que repercutem em bons resultados metodológicos para o ensino nas diversas áreas do conhecimento na educação infantil.Essa repercussão ocorre pelo fato de a idade escolar e o crescimento biológico da criança serem beneficiados com essas alternativas. Contudo, como também apontado, o método exige no que se refere ao planejamento das atividades, visto que há a necessidade da adequação e trânsito entre os movimentos, as expressões, a lógica de raciocínio, as regras, o desempenho hierarquizado e etapista, o uso de equipamentos e/ou instrumentos e os conteúdos curriculares que a professora deseja exercitar. Este manuseio só é conseguido com a experiência escolar e ou saber acumulado do próprio exercício de ensino. 
Nesse quesito, na análise dos planos de aula percebemos que estavam bem elaborados, em acordo com o Currículo e conteúdos propostos, demonstrando boa articulação dos vários campos. Mesmo com a falta de experiência da professora, foi notório o seu esforço para conseguir "dar conta" em trabalhar os conteúdos, tentando usar recursos metodológicos variados, comoos lúdicos, mesmo não conseguindo contemplar em todas as aulas um momento para as brincadeiras e atividades lúdicas, pois, como ela mesma afirmou, não são todos os conteúdos que consegue ministrar, alguns precisam ser trabalhados mais na oralidade.

Grande parte dessa dificuldade, como podemos perceber, foi em razão da característica heterogênea da turma. As dificuldades individuais, anteriormente descritas, foram a principal barreira para que o resultado fosse mais satisfatório. O grupo se apegou muito mais ao lúdico livre do que à compreensão e execução das regras.

A formação recente da professora também foi um fator incidente, visto que ainda não há acúmulo de saber fazer. Esta lacuna, porém, no caso da professora que acompanhamos, será seguramente superada, em razão do seu empenho em compreender e planejar.

Resta apontar ainda que os autores arrolados sobre o assunto e outros consultados, focaram o esforço em demonstrar as brincadeiras e jogos como um caminho metodológico para o ensino. Não encontramos, no entanto, autores que enfocassem o aluno como sujeito real e ou que descrevessem os resultados de aplicação desse método. Assim, constatamos que existe uma grande literatura em defesa, mas muito pouca sobre a descrição dos modos de aplicação e da descrição do público alvo, ou seja, o aluno.

Nesse sentido, esta pesquisa e a procura de fontes que a professora descreveu apontaram para o mesmo ponto: há pouca literatura que trate sobre o exercício de ensino em áreas determinadas - História, Geografia, Matemática, Português - com esse método. Parecer ser mais "obvio" ou menos complicado deslocar-se por entre conceitos do que por entre pessoas. 
Ao mesmo tempo, a etnografia escolar permitiu perceber a espontaneidade infantil para os jogos e brincadeiras. Tais experiências apontam também para o fato de que elas próprias inventam e criam regras de usos e de relações entre si. Isto ficou factível quando a professora explicou as regras do uso, por exemplo da bola para demonstrar o tipo de superficie, mas as crianças queriam outro jogo, resistiram e perderam o interesse pela atividade dirigida. Neste interim, é preciso inverter o papel de quem ensina e quem aprende: a professora deveria ser expectadora e observadora de quais regras eles estariam jogando "livremente" e reinserir os seus objetivos. Enfim, estes elementos devem ser instigantes de outras pesquisas.

\section{Referências}

ANDRÉ, M. E. D. A. A pesquisa no cotidiano escolar. In: FAZENDA, I. (Org.). Metodologia da pesquisa educacional. 6. ed. São Paulo: Cortez, 2000. p. 3545.

ARCE, A. O referencial curricular nacional para a educação infantil e o espontaneísmo: (re)colocando o ensino como eixo norteador do trabalho pedagógico com crianças de 4 a 6 anos. In: ARCE, A.; MARTINS, L. M. (Org.). Quem tem medo de ensinar na educação infantil? Em defesa do ato de ensinar. 2. ed. Campinas: Alinea, 2010.

ARIÉS, P. História social da criança e da família. Tradução Dora Flaksman. 2.ed. Rio de Janeiro: Guanabara, 1986.

BRASIL. Ministério da Educação e do Desporto. Secretaria de Educação Fundamental. Referencial curricular nacional para a educação infantil. Ministério da Educação e do Desporto, Secretaria de Educação Fundamental. Brasília: MEC/SEF, 1998.

CASCAVEL (Municipio). Secretaria Municipal de Educação. Currículo para a rede pública de ensino de Cascavel:CASCAVEL. Secretaria: Volume I: (Educação infantil). Cascavel, 2008.

CHARLOT, B. Da relação com o saber: elementos para uma teoria. Porto Alegre: Artes Médicas Sul, 2000.

ELKONIN, D. B. Sobre o problema da periodização do desenvolvimento psíquico na infância. In: DAVIDOV, V.; SHUARE, M. (Org.) La psicología evolutiva y pedagógica en Ia URSS: Antologia.Moscou: Progreso, 1987, p. 104124.

EVANS, V.; GREEN, M. Cognitive Linguistics. An Introduction. New Jersey, London: Lawrence Erlbaum Associates Publishers, 2006.

FACCI, M. G. D. A periodização do desenvolvimento psicológico individual na perspectiva de Leontiev, Elkonin e Vigotski.Cadernos CEDES, Campinas, v. 24, 
n. 62, p. 64-81, abril, 2004.Disponivel em: <http://www.cedes.unicamp.br/>. Acessoem: 08 Abr. 2017.

LAKOFF, G.; JOHNSON, M. Metaphors We Live by. Chicago: The University Press, 1980.

LEONTIEV, A. N. O desenvolvimento do psiquismo. Lisboa: Livros Horizonte, 1978.

MINAYO, M. C. S. Ciência, técnica e arte: o desafio da pesquisa social. In: MINAYO, M. C. S. (Org.). Pesquisa social: teoria, método e criatividade. 18. ed. Petrópolis: Vozes, 1994. p. 9-29.

. O desafio do conhecimento: pesquisa qualitativa em saúde. 7. ed.

São Paulo: Hucitec; Rio de Janeiro: Abrasco, 2000.

OTTONI, T. P. M. E.; SFORNI, M. S. F. Vigotski, Leontiev e Elkonin: Subsídios teóricos para a Educação Infantil.ENDIPE- Encontro Nacional de didática e práticas de ensino, 16, 2012, Campinas, SP. Anais... Campinas: UNICAMP, 2012.

PINTO, M. A infância como construção social. In: PINTO. M.; SARMENTO, M. J. As crianças: contextos e identidades. Braga: Centro de Estudos da Criança, Universidade do Minho, 1997.

RAMOS, D. C.; RIBEIRO, S. M.; SANTOS, Z. A. G. Os jogos no desenvolvimento da criança. In: ROSA, A. (Org.). Lúdico \& Alfabetização. Curitiba: Juruá, 2011, p. 38-43.

RODRIGUES, L. da S. Jogos e brincadeiras como ferramentas no processo de aprendizagem lúdica na alfabetização. 2013. 97 f. Dissertação (Mestrado em Educação). Faculdade de Educação, Universidade de Brasília, 2013.

SPERANÇA-CRISCUOLO, Ana Carolina. Funcionalismo e cognitismo na sintaxe do português: uma proposta de descrição e análise de orações subordinadas substantivas para o ensino / Ana Carolina Sperança-Criscuolo. São Paulo: Editora Unesp Digital, 2014.

VIGOTSKY, L. S. A formação social da mente: o desenvolvimento dos processos psicológicos superiores.Tradução do grupo de Desenvolvimento e Ritmos Biológicos, Departamento de Ciências Biológicas da USP. São Paulo: Martins Fontes, 1998.

VIGOTSKY, L. S. Obras escolhidas II. Madrid: Visor, 1982.

A formação social da mente: o desenvolvimento dos processos psicológicos superiores. 6. ed. São Paulo: Martins, 1984. 